\section{ON THE DISSEMINATION OF CANCER OF THE BREAST,}

AND THE NECESSITY FOR ITS TREATMENT BY EXTENSIVE OPERATION.

[With Special Plate of Microscopic Sections.]

BY HAROLD J. STILES, M.B., F.R.C.S.EdIN.

Surgeon to the Royal Edinburgh Hospital for Sick Children, and Senior Demonstrator of Surgery in the University of Edinburgh. [From the Surgical Laboratory of the University of Edinburgh.]

\section{Complete_and INCOMPLETE OPERATIONS.} Clinical Evidence.

IT is now just a decade since Heidenhain ${ }^{1}$ published his important and classical paper upon the causes of recurrence after operation for cancer of the breast. In a communication ${ }^{2}$ dealing with my own researches on the same subject, I was able to confirm, and to some extent also to extend, the obser. vations of Heidenhain. The practical and therapeutic significance of the anatomical and pathological observations emboried in these two researches have been duly recognised by many surgeons, and have been largely instrumental in inducing them to revise the operation formerly adopted for cancer of the breast. Cheyne, Halsted, Rotter, Kocher Butlin, Helferich, and many others have worked out and developed an operative procedure which, by meeting the pathological requirements, offers a fair prospect of ridding the unfortunate sufferer of what was, and is even now, too often regarded as an incurable disease.

In the early part of last year a paper upon Immunity and Latency after Operations for Reputed Cancer of the Breast, read before the Royal Medical and Chirurgical Society of London by Mr. Marmaduke Sheild, led to an important discussion, which resolved itself practically into a debate upon the comparative value of the old and the new operations. The debate was deemed of such importance that it was twice adjourned, and many of the leading London surgeons took part in it. Most of the speakers, with the important exceptions of Cheyne and Butlin, objected strongly to applying the word "cured" to patients who had survived the operation for three years without manifesting any signs of recurrence, and many cases were brought forward by $\mathrm{Mr}$. Sheild and others in which patients who had been subjected to the old operation had survived a much longer period. Such patients, however, owed their good fortune to the eccentricities of their disease rather than to the operation. The vagaries of cancer are such that an incomplete operation may occasionally give the same freedom from recurrence as a more extensive one. As long, however, as we are unable to single out such cases, the old operation, performed with the object of caring the patient, is unjustifiable. "Incomplete" the old operations certainly were, and the sooner this is recognised the better will it be both for the patient and for the credit of modern surgery. It is a mistake to suppose that the ultimate prognosis in patients free from recurrence three years after the old operation is as good as in the case of a patient who is free from recurrence three years after a modern extensive operation. In the former case the patient still runs the risk of local as well as of internal recurrence, whereas in the latter case the risk is limited to a very large extent to internal recurrence only, for the simple reason that the tissues in which local recurrence so commonly occurs have been removed. By a "complete" operation is meant one which prevents external recurrence; but no operation can be termed complete in the sense of preventing internal recurrence, for internal metastases may already exist at the time of operation, and it is the duty of the surgeon to ascertain, as far as possible, if such be the case.

In the face' of the arguments and results which $\mathrm{Mr}$. Cheyne was able to bring forward (in his Lettsomian Lectures for 1896) in favour of the modern extensive operation for cancer of the breast, one can only express surprise that so many eminent and experienced surgeons should have spoken so favourably of the old operation.

Many surgeons in the discussion above referred to, complained of the use of the terms "incomplete" and "complete," which were used to designate the old and new opera- tions respectively. Mr. Cheyne, I believe, was mainly responsible for the use of these terms, and I am bound to say that if proofs were needed to justify his using the term "incomplete" to designate the old operation, no better could be brought forward than are furnished by contrasting the results of his own operation with even the most favourable of those obtained by the old operation. In his "Further statement as to results obtained by operation for cancer of the breast," 3 he has, in my opinion, gone a long way towards justifying the use of the word " cured," as applied to cases which have been operated on in the manner he describes. Taking the i2 out of the 21 patients who had been free from recurrence three or more years after the operation, Mr. Cheyne finds that one died from acute bronchitis without any recurrence three years and five months after operation; one, known to have been well a year ago, has not been traced; one is said to have died of cancer of the intestines, while the remaining nine are all alive and well at periods varying from six to nine years after operation. Taking all the cases which Mr. Cheyne has operated on since 1890,51 per cent. are alive and well three or more years after operation. These cases are now referred to by Mr. Cheyne as "successes" in place of "cures." Further, Mr. Cheyne's results bring out the important fact that a distinctly hopeful prognosis may be given in cases where only one year has elapsed without recurrence, provided, of course, a sufficiently radical operation was performed.

Pathological Evidence.

Although no better or stronger proof could be brought forward in support of the value of extensive operations in cancer of the breast than is afforded by their results, I may be pardoned if in this paper I endeavour once more to demonstrate that, on pathological grounds, such operations are necessary if the patients are permanently to be rid of the disease.

The following remarks are founded upon the careful nakedeye and microscopic investigation of over 100 breasts removed by the staff of the Edinburgh Royal Infirmary and of the Chalmers Hospital during the first half of the present decade. By the courtesy of the staff of these hospitals I was permitted to examine the greater number of the cases before operation, and was present at the operation. The parts removed were investigated by me in the surgical laboratory of the University of Edinburgh, where I received much encouragement and many valuable suggestions from Professor Chiene.

\section{NaKeD-EYe ANATOMY.
The Nitric-acid Method.}

In order that the anatomy of the gland and the distribution of the disease could be satisfactorily studied by the naked eye, it was found necessary in the first place to obtain a method which would differentiate the epithelial from the connective tissue structures. A 5 per cent. solution of nitric acid was employed for this purpose in the manner originally described by the writer. ${ }^{2}$ This reagent, by coagulating the protoplasm of the epithelial cells, and at the same time partially gelatinising the connective tissue, gave the required differentiation. Although the cancerous and the normal epithelium react in the same manner, they could generally be differentiated after a little experience by observing the differences in their distribution and arrangement. In cases in which this could not be done by the naked eye, the microscope was employed to settle the question. Space will not permit me to describe the anatomy of the breast, or to refer to the great variations which are met with, depending for the most part upon the age of the patient and the functional state of the gland. With regard to the cancerous tissue, the nitric acid not only defines very clearly the limits of the tumour, but, what is more important, by enabling one more readily to detect small foci of disease in the gland and adjacent tissues, this reagent affords us a means of studying the dissemination of the disease.

\section{The Routes of Local Dissemination.}

Since pathologists are now agreed that carcinoma is primarily a local affection, it is clearly the duty of the surgeon to endeavour to remove not only the entire breast, but as far as possible as much of the adjacent tissues as is liable to be involved in the dissemination of the disease. It must not be supposed that disseminated foci of cancer are visible to 
the naked eye in every cancerous breast, even by the aid of nitric acid; indeed, in the early stage of a typical circumscribed scirrhus it is the exception, rather than the rule, to meet with them. By the examination, however, of a large number of breasts in which such foci are visible, we acquire a considerable knowledge of the channels along which the disease is liable to be disseminated. And when no foci are visible to the naked eye, careful microscopic investigation will frequently reveal their presence, so that, whether visible or not, all those tissues in which we are accustomed to find them must be looked upon with suspicion, and removed, however limited and circumscribed the tumour may appear. Unfortunately our knowledge of the dissemination of cancer is not sufficiently extensive to allow us to state precisely in any given case when, or in what order, and in what direction, the various tissues become involved. As, however, the cancer cells have necessarily occupied the lymphatic spaces for some time before the tumour can be detected clinically, it is only reas onable to suppose that a certain amount of dissemination will in all probability have taken place by the time the case comes under treatment.

The writer, in his demonstrations on surgical pathology to the senior students of the class of surgery in the University of Edinburgh, has for some years been in the habit of demonstrating the morbid anatomy and mode of dissemination of cancer of the breast by means of photomicrographs-the work of Mr. Andrew Pringle, of London, and of Mr. Richard Muir, of the Pathological Department of the University of Edinburgh, to both of whom I desire to express my indebtedness and thanks-selected from many hundreds of preparations. With the exception of Mr. Cheyne's article on the breast in Treves's System of Surgery, in which a few of these photographs have been reproduced, even in the latest textbooks on surgery and works on diseases of the breast, although the morbid histology of the different varieties of cancer is figured, no illustrations are given demonstrating the lymphatic dissemination of the disease and the need for the modern extensive operation. If by giving the gist of these demonstrations I succeed in proving the necessity of such operations, this paper will not have been written in vain.

The Characters of the Breast Tumour.

As regards the tumour itself, it is generally met with in the form of a more or less hard growth, which although not encapsulated is generally well circumscribed. It may occupy any part of the breast, and when growing in the extremity of one of the peripheral processes, more especially of the outer hemisphere, may give rise to the erroneous impression that it has originated outside the mamma. When the tumour is growing in the deeper layers of a large, fat mamma the tumour may either escape detection altogether, or be mistaken for a localised mastitis, in consequence of its outline being obscured by the fat. An atrophic scirrhus, situated subjacent to the nipple, is often difficult to detect on account of the thickened and indurated condition of the skin about the areola.

Less frequently the cancer instead of forming a circumscribed tumour is more or less diffused throughout the whole breast, and this form of the disease may, like the nodular form, occur as a diffuse, slow-growing atrophic tumour, or in the form of a rapid and more acute general enlargement (acute or inflammatory cancer). This condition is liable to be mistaken for a subacute general mastitis, but may generally be distinguished by the early involvement of the skin.

The colloid variety of cancer, which is met with in not more than 2 or 3 per cent. of cases of cancer of the breast cannot as a rule be diagnosed clinically. In history and physical signs this variety of tumour stands midway between fibro-adenoma and scirrhus. It is slow growing, well-defined, and sometimes has a bossy surface; the glands in the axilla, although they may be slightly enlarged, are very rarely malignant. It differs from fibro-adenoma in being nonencapsulated, and therefore not mobile apart from the breast and in having more the consistence of a scirrhus than that of a fibro-adenoma.

Turning now to the main subject of this article-that is to say, the mode of dissemination of the disease-it must be distinctly understnod that the preparations which have been used to illustrate the text were not derived from one breast, but have been selected from a large series. On several occasions, on examining cancerous breasts in which no disseminations were visible to the naked eye, I have come across, as it were by accident, cancerous emboli in lymphatics far removed from the primary tumour, occupying sometimes breast tissue, at other times the adjacent tissues-skin circum-mammary fat, pectoral fascia. As regards the spread of the disease in the breast tissue itself, we have to consider, first, the part played by the gland parenchyma.

\section{Spread of the Disease in the Breast.}

Given, then, an ordinary scirrhus of the breast, according to the views of Heidenhain there are present throughout the whole breast proliferative changes in the epithelium of the parenchyma and in the interacinous connective tissue, which must be looked upon as precancerous, sooner or later destined to develop into typical cancer. Now that we know how widely the breast tissue extends, and how frequently peripheral processes are left behind, it becomes important to consider the part any breast tissue which escapes removal would play in the production of recurrence. My own observations lead me to conclude that, when cancer manifests itself in breast tissue which has been left behind, the disease is far more likely to originate from cancerous emboli lurking in the lymphatics of the breast tissue than from the epithelium of the parenchyma ; in other words, that recurrence from breast tissue which has been left behind originates in the same way as recurrence in the tissues extrinsic to the mamma-for example, in the skin and pectoral fascia. This question, although of great interest to the pathologist, is of less importance to the practical surgeon since in removing all the lymphatics of the breast he must of necessity also remove all the parenchyma.

In many cancerous breasts the gland tissue differs in no respect from that found in non-cancerous breasts. The proliferative changes which Heidenhain and others regard as precancerous are very commonly met with in various forms of mastitis and cystic disease, and yet it is the exception for these affections to become malignant. The principle, therefore, that should underlie all operations for carcinoma of the mamma is complete removal, not only of the breast; but also of as much of the surrounding tissues as is likely to contain the lymphatics along which cancer cells may be disseminated. Unfortunately, it is impossible in any given case to say to what extent this dissemination may have taken place, and herein lies the difficulty and uncertainty of the operative treatment of malignant disease.

\section{Microscopical ANatomy.}

However well defined the outline of the primary tumour may appear to the naked eye, microscopically the essential elements of the tumour, that is to say, the cancer cells, insinuate themselves into the lymph spaces of the adjacent tissue. By continued proliferation the cells come to be arranged in irregular, anastomosing clusters, which dilate the lymph spaces into the. so-called alveolar spaces of the stroma; the latter consists partly of the pre-existing tissue and partly of a newly-formed tissue, the result of an inflammatory hyperplasia of the connective tissue, set up by the irritation produced by the proliferation of the cancer cells, and no doubt also by their chemical products. In the meshes of the stroma leucocytes are generally met with, and these are more or less numerons according to the degree of irritation. Microscopically the tumour tissue may be distinguished from the adjacent gland parenchyma, not only by its lack of gland-like architectural arrangements, but also by the difference presented by the morphological characters of the cells in the two cases. Without going into details of cell structure, suffice it to say that the cells of the tumour, especially their nuclei, are much larger, and show signs of greater reproductive activity than the cells of the gland parenchyma.

"Cancer Cells."

These structural differences are comparable with, and no doubt co-related to, the functional differences, and are sufficiently marked to justify us in applying the specific term "cancer cells" to the modified and malignant epithelial cells of the tumour. Of what it is that brings about this very remarkable modification, both of structure and function; on 
the part of the epithelial cells, we are as ignorant as ever. To settle this question would be to solve the cancer problem, and possibly also to lead to the discovery of a method of succesofully dealing with the disease. without resurt to the knife. I have no intention of entering upon the vexed question of the parasitic causation of cancer iurther than to say that I have devoted much time to an endeavour to elucidate the nature of the cancer bodies originally described by Ruffer and Plimmer ${ }^{4}$ as protuzoa, and subsequently by Sanfelice, ${ }^{5}$ Roncali, and other Italian observers as belonging to the blastomycete variety of fungi. I must confess I had satisfied myself that these structures were not parasites, and that I was able to trace their evolution from the cancer cells themselves. It is to be hoped, how $v^{*} r$, that the very interenting and important work recently published by Plimmer ${ }^{6}$ may settle the question. Without having heard Mr. Plimmer's paper, or having seen his preparations and cultivations, one is verhaps hardly justifit $d$ in offering any criticism; but the questiou which presented itself to my mind was as to the possibility of the cultures consisting of proliferated and degenerated cancer cells themselves-a possibility which must be reckoned with if we reflect upon the reproductive activity which epithelial cells are capable of retaining when transferred to a suitable soil. Agaiu, the peculiar morphologicul appearances which cancer cells present when growing in the fluid of a malignant pleurisy seems to justify such a possibility.

Spread along Lymphatics. a mammary cancer. In the upper half of the field clusters of cancer cells are seen invading the fat of the interlobular breast tissue; in the lower half of the field is an atrophied gland lobule, consisting of the finer ramification of a duct, round which are grouped a few atrophied acini filled with small epithelial cells. Close outside this atrophied lobule are a few clusters of cancer cells which are much larger than the epithelial cells of the acini. By comparing the cells of the oancer with those of the gland parenchyma, placed thus side by side, one gets a good idea of the relationships of the one to the other, and learns to distinguish the two kinds of cells when met with independently. In the right upper quadrant are two blood vessels, accompanied by two paravascular lymphatic vessels distended with cancer cells. This section may be taken as an example of what happens when a cancer invades and spreads amidst the breast tissue itself, and shows that it makes its way into the lymph spaces and lymphatic vessels. Having gained the lymph vessels a few cells may at any time be transplanted by the lymph stream to a lymphatic gland, or may be arrested as emboli at any point along the lymph channel which leads to the lymphatic gland. Further, it is to be noted that the adjacent parenchyma becomes invaded and destroyed by the onward march of the proliferating cancer cells. The interacinous connective tissue undergoes a more or less well-marked chronic inflammatory hyperplasia, but the epithelial cells of the acini seldom show signs of becoming cancerous; in other words, the cancer cells do not appear to exert any spermatic, fertilising, or infective power over them. In Fig. 2, taken from a part of the tumour invading the nipple, one of the main lactiferous ducts is seen to be surrounded by clusters of cancer cells, the whole appearance resembling somewhat a duct surrounded by acini filled with large cells. They are not acini, however, the cells of which have undergone a cancerous transformation; they are the lymphatics which occupy the adventitious coat of the duct, injected as it were with cancer cells. These two preparations then may be taken as illustrating ( 1 ) the local origin of the tumour; (2) its spread along the lymphatics-paralobular, paraductal, interlobular, and paravascular-of the breast tissue; (3) the more or less passive part played by the adjacent gland parenchyma.

In diffuse cancers of the breast the preparations treated by the nitric acid method show isolated and conglomerate foci of cancer, scattered throughout the greater part of the breast. In such cases it is not always possible to say which foci are the result of lymphatic dissemination and which have originated as independent outbreaks of cancer from the parenchyma. It is just in these cases that we might expect to find the precancerous, or what is sometimes termed the adenomatous, stage of cancer, and to be afforded a demonstration of the various stages in the transition from normal parenchpma into cancer; but it is seldom that such transitions are to be found; the tissue is generally either distinctly cancerous or distinctly non-cancerous. In the instances in which we do find proliferative and hypertrophied epithelium in the gland parenchyma, it is difficult to say whether or not such cases are to be regarded as precancerous, inasmuch as precisely similar changes are met with in various forms of chronic mastitis, cystic disease. I cannot agree with Heidenhain in regarding the parenchyma of a breast which is the seat of an ordinary circuwscribed scirrhus as necessarily precancerous throughout. Since, however, the more diffuse cancers show us that the disease may break out in the form of independent foci, we must admit the possibility of the same thing happening in a breast the seat of a circuuscribed tumour, should the disease be allowed to run its course. For this reason, therefore, it is safer to remove the entire breast. But a far more important reason for removing the whole breast is in order that we may be sure of removing any pre-existing cancer cells which may have been transplanted either directly or indirectly from the primary tumour, and which may ke lurking in the lymph spaces and lymphatics of the stroma.

\section{Transitional Stages.}

The breast tumours in which transitional stages in the development of cancer may be most conveniently studied are :

I. Those in which the cancer has followed upon an antecedent mastitis, and

2. A group of epithelial tumours which have been singled out by Halsted ${ }^{7}$ as possessing distinctive clinical and histological features, and which he proposes to designate under the name "adeno-carcinoma." He has met with five or six examples of this variety of tumour in about 150 cases of breast cancer. Thanks to the excellent plates which accompany the text, there is no difficulty in identifying the three or four cases which have come under my notice. Surgeons will do well to make themselves familiar with their clinical features, because, possessing a somewhat encephaloid appearance, and having a tendency to fungate they are liable to be looked upon as possessing a high degree of malignancy, whereas, in reality, they are, as Halsted has shown, much less malignant than the ordinary scirrhus, since they rarely give rise to secondary growths in the glands, or to local recurrences. They are perhaps most closely allied to the duct cancers.

From what $I$ have seen of cancers developing in connection with chronic mastitis, I am inclined to think that though they possess a distinctly higher degree of malignancy than is displayed by the adeno-carcinomata of Halsted, they are, nevertheless, less malignant than the ordinary scirrhus ; this is probably to be accounted for by the fact that the cicatrisation of the inflammatory tissue tends to narrow or obliterate the lymph channels.

Breast Tissue and Recurrence.

As bearing upon the part which breast tissue when left behind plays in causing recurrence, I may refer to what was found in two recurrent tumours. In one the recurrent nodule, which did not appear until nine years after the first operation, was situated close to the inner extremity of the cicatrix, just outside the edge of the sternum. Microscopic examination revealed the fact that the cancerous nodule was invading some atrophied breast tissue adjacent to it. In the second case, the recurrent tumour, which was the size of a walnut and bore a close resemblance to a primary tumour, appeared to be situated just below the lowest limit of the mammary area, yet on nitric acid examinination of the parts removed, typical gland parenchyma, in the form of a grape-like clustering of ultimate lobules, could readily be made out. Some of these were actually seen upon the exposed surface of the mass removed, which shows that some gland tissue had been left behind even after the second operation. The specimens derived from these two cases were subjected to careful microscopic investigation in order, if possible, to determine whether the recurrent tumours had originated from cancerous lymphatic emboli, or from the gland parenchyma which had been left behind at the first operation. In both instances the tumour tissue, which was of the typical scirrhus type, invaded the adjacent parenchyma, but the latter differed neither in 


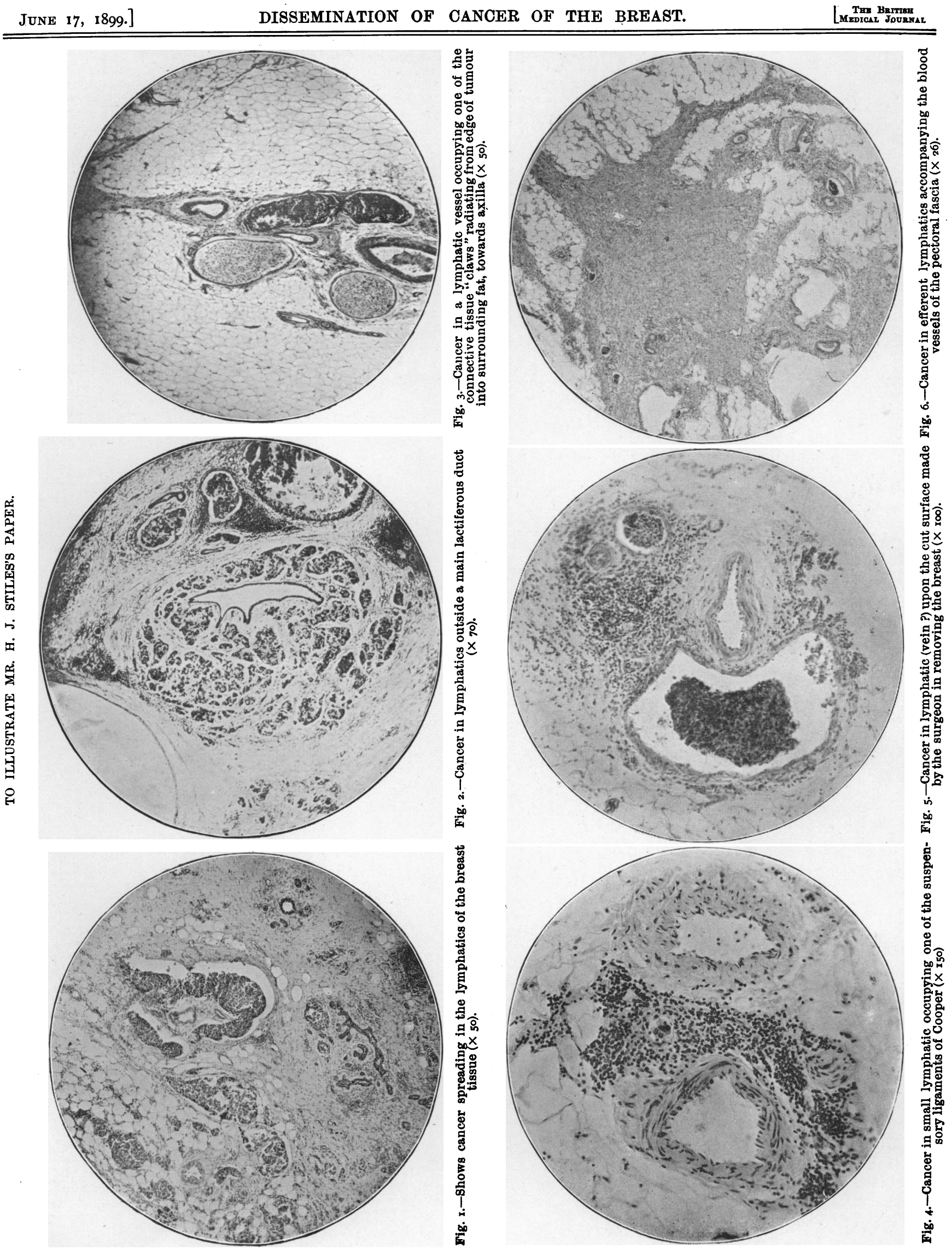



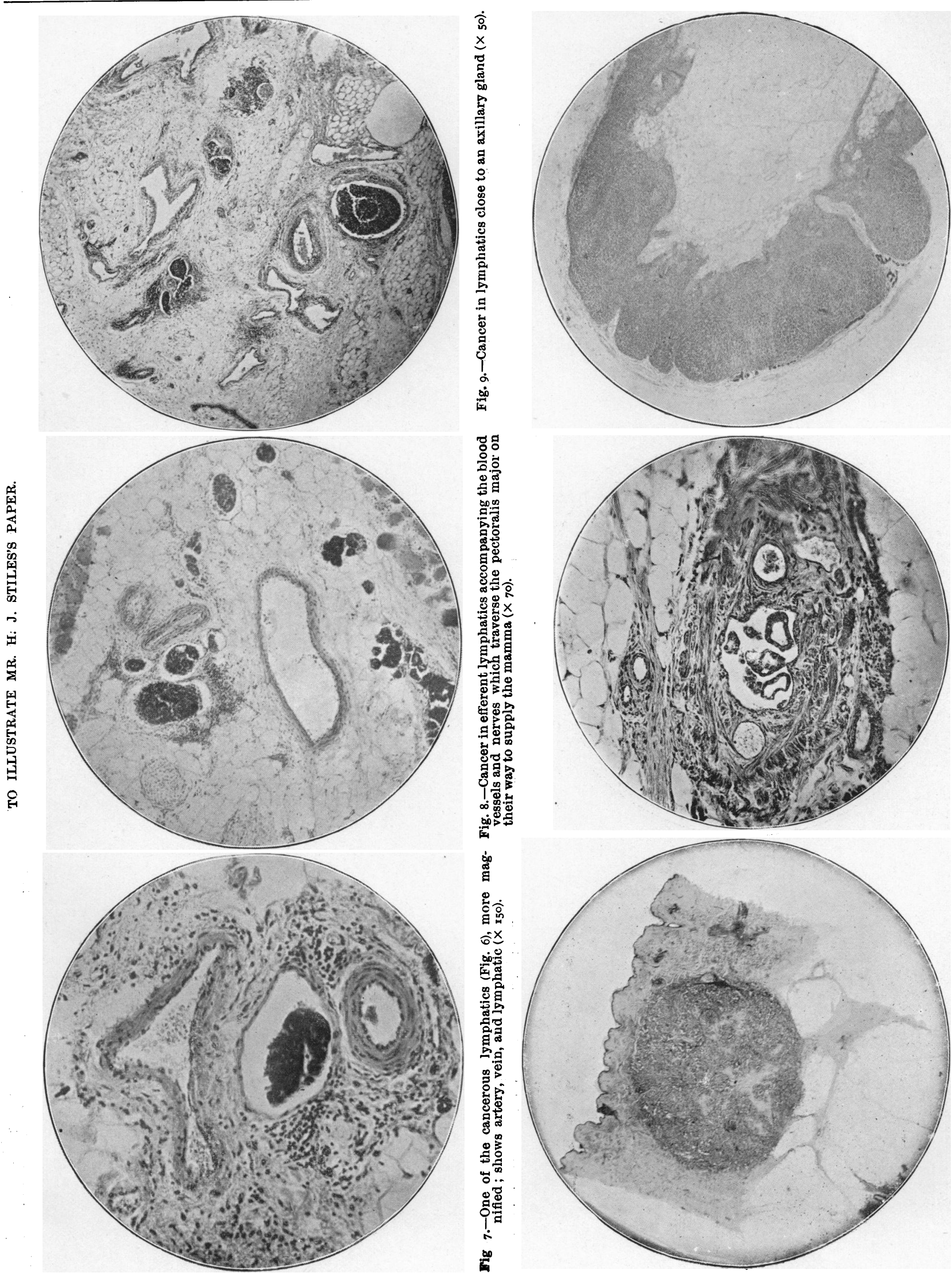

胥

淧

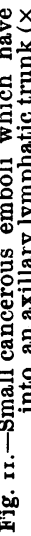
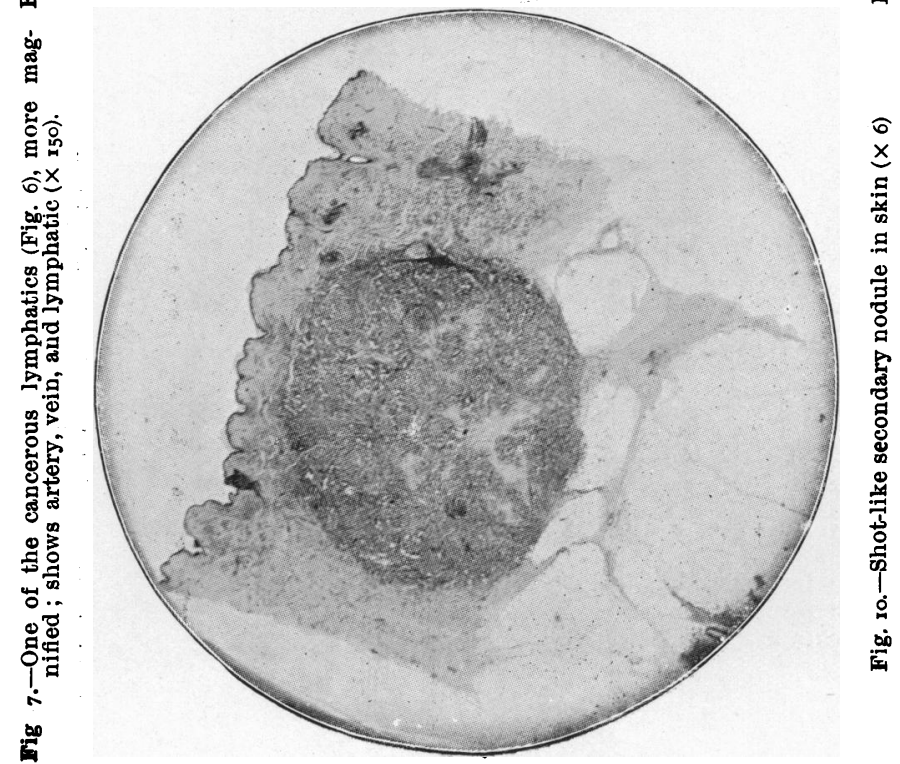
arrangement nor in structure from what one is accustomed to find in non-cancerous breasts; the interacinous connective tissue was rather more cellular than normal, but there was no proliferation or hypertrophy of the epithelium of the aciniin short, no changes which could be regarded as precancerous. It was impossible to say, therefore, whether these two recurrences had originated from cancerous lymphatic emboli, or as fresh outbreaks from gland parenchyma. The fact, however, that they had originated in the midst of the breast tissues raises the suspicion that they may very probably have been fresh outbreaks from the parenchyma, and, if so, then it becomes all the more necessary that the surgeon should remove every trace of gland tissue.

In this connection I may refer also to a cancerous breast which contained an ordinary involution cyst situated in the opposite hemisphere to that of the tumour. Microscopic pre parations were made for the purpose of demonstrating the structure of the wall of the cyst and its relation to the adjacent parenchyma. To my surprise I found two or three small cancerous emboli occupying the lymphatics of the breast tissue just outside the wall of the cyst. The parenchyma in the neighbourhood was quite normal. If this piece of breast tissue had been left behind, then, by the time, that the recurrent tumour had become manifest clinically, it would no doubt have been impossible to say what was the origin of the recurrence, but in all probability the blame would have rested with the parenchyma. I might instance many other examples of the accidental finding of cancerous emboli in breast tissue far removed from the primary tumour; indeed, I have found them in sections taken from the exposed surface of the parts removed, a good example of which will be found in Fig. 5. It must not be supposed, however, that in carcinomatous mammæ the lymphatics throughout the gland are extensively and continuously filled with cancer cells; in some breasts-more especially those which are the seat of diffuse cancer-emboli are numerous ; in others, sections from many parts of the breast have to be examined before any emboli can be discovered; in others, again, careful search fails to find them, but, as complete microscopic investigation of the entire mamma is practically impossible, it would be rash to conclude that none exist.

In successful microscopic preparations there is, as has been already stated, no difficulty in distinguishing the cancer cells from the epithelium of the gland parenchyma, so that the relation of the one to the other can readily be studied. I have repeatedly found cancer cells occupying the lymphatics in all the situations in which Langhans has succeeded in injecting them artificially. In many instances, owing to shrinkage of the cancerous emboli, the endothelial lining of the lymphatics may readily be made out.

\section{The Paravascular Lymphatics.}

Besides the lymphatics which are closely related to the parenchyma-namely, the interacinous, the perilobular, the interlobular, and the periductal lymphatics-there are other intramammary lymphatics which are more closely related to the blood vessels. These may with advantage be spoken of as the paravascular lymphatics, and since the lymphatics above mentioned open into them, they may be looked upon as constituting the main effluent lymphatic channels by which the lymph is drained from the breast. When patent, these lymphatic vessels can be readily seen and studied. In structure they are exceedingly simple, consisting of a layer of endothelium, immediately outside of which is the unmodified connective tissue, forming a sheath to the blood vessels which the lymphatics accompany. As far as I am aware, in the mamma 1tself there are no lymphatics, the walls of which are furnished with non-striped muscular fibres. These paravascular mammary lymphatics are generally larger than the small veins and arterioles which they aecompany and surround more or less completely. Sometimes the blood vessel is seen to occupy the centre of a large perivascular lymphatic sheath. In the majority of instances the lymphatics in ordinary histological preparations are empty and collapsed, and thereby escape notice. When cancerous, they are generally filled and distended with cancer cells, which may or may not have penetrated their walls and invaded the surrounding tissue. Occasionally one may observe a patent lymphatic containing a few cancer cells which appear to be floating in the lymph stream; the endothelial lining of the lymphatic is then quite distinct, and $I$ have never seen appearances indicating that the endothelium becomes cancerous.

The Blood Vessels and Lactiferous Ducts.

It is by no means always easy to say whether a cancerous embolus is occupying the paravascular lymphatic or a small vein. Goldmann, in an able and important monograph, has demonstrated, by the aid of orcein, a specific stain for elastic fibres, that the blood vessels, especially the small veins, are more frequently and more extensively invaded than was hitherto thought to be the case. The wall of the vein is usually attacked directly from without, but the cancer cells are, as a rule, prevented from gaining free access to the lumen of the vessel by an advancing barrier of connective tissue, caused by the chronic inflammatory hyperplasia which the cancer cells set up in the wall of the vessel; in some cases there is formed an organised thrombus containing cancer cells which blocks the lumen of the vessel, and in this way prevents a more general invasion by the blood stream. More rarely the arteries become invaded, and it is possible that the sudden formation and extensive distribution of lenticular disseminations in the skin may, in some instances, be due to arterial embolism. Goldmann has also shown that the walls of the lactiferous ducts may become invaded in much the same way as the blood vessels, and should the cancer cells gain access to the lumen, they may, by their subsequent proliferation, give rise to a condition which cannot always be distinguished from an independent outbreak of cancer, starting from the epithelial lining of the duct.

Paget's Disease of the Nipple.

In that interesting affection known as Paget's disease of the nipple, the malignant epithelial cells, which either originate in, or gain access to, the ducts, subsequently spread along them, destroying the adjacent normal epithelium in their advance. In microscopic preparations consisting of longitudinal sections of a nipple, one can frequently trace the malignant disease from the surface of the nipple down some of the ducts, until a frontier is reached where there is a marked line of demarcation between the cancerous and normal epithelium. Others of the main ducts may be quite free from the disease, and in others again one half of the lumen may be cancerous, while the other half is normal. I cannot make even this incidental reference to Paget's disease without taking an opportunity of mentioning that the so-called psorosperms are nothing more nor less than epithelial cells which have become hypertrophied, vesicular, and succulent-looking, and which have taken on proliferative activity, as shown by the frequent presence of mitotic figures, which, in short, have undergone a malignant transformation. As Karg ${ }^{9}$ rightly points out, the so-called psorosperms are the first cancer cells. Why they should crop up here and there, sometimes single, sometimes in pairs, sometimes in small clusters, and sometimes in groups in the deeper layers of the epidermis is difficult to understand. In Paget's disease we come nearer to a demonstration of the actual initial stage of malignant disease than is afforded by any other forms of carcinoma with which I am familiar. But whence and wherefore the origin of the malignant cell or cells, surrounded on all sides by perfectly normal epithelium? The study of some specimens tends to confirm the observations of Karg that all transitions may be made out between the cancer cells and the normal epidermic cells. If it were not for the fact that the malignant cells were situated deep down in the epidermis, and often covered by many layers of normal epithelium, I should be inclined to say that some of the cells which had escaped from the orifices of the cancerous lactiferous ducts had got implanted upon the surfa $3 e$ and there taken root. It must be confessed, however, that the histological appearances alone, without other considerations, tend rather to negative this view. The same stimulus, whether a contagium vivum or not, is no doubt responsible for the malignant action which has been taken on both by the epithelium of the lactiferous ducts and by that of the adjacent epidermis. That the disease begins at or near the mouths of the ducts, and spreads from thence both down the ducts and circumferentially in the skin, there can, I think, 
be little doubt. But why the disease should spread in the skin in the form of foci, limited to the epidermis, is a question which makes Paget's disease of the nipple one of the most interesting of the histological problems connected with cancer.

Mode of Spread in Extrinsic Mammary Structures.

While, then, breast tissue may occasionally be demonstrated in the neighbourhood of recurrent nodules, it must be admitted that in the majority of cases no breast tissue is to be discovered. This leads us to the consideration of the mode of spread of the disease in the extrinsic mammary tissues-the skin, circum-mammary fat, pectoral fascia, and pectoral muscle. Any or all of these tissues may of course be directly invaded by the main tumour. When the skin becomes involved and ulcerates, or when the tumour fungates, the epidermis becomes destroyed; its epithelium takes no part in the cancerous process-that is, the cancer cells of the tumour possess no infective influence, capable of endowing the epidermis with malignant properties. When the tumour is situated under the areola the cancer cells gain early access to the lymphatics, which occupy the adventitious coat of the main lactiferous ducts.

The Subareolar Lymphatic Pleaus.

These lymphatics open into the rich subareolar plexus of Sappey, which in its turn is in free communication with the cutaneous system of lymphatics. Central tumours, therefore, are peculiarly liable to produce induration about the nipple and areola, and to give rise to extensive infection of the skin. In the form of the disease known as cancer en cuirasse, in which the skin of the chest becomes indurated, thickened, tuberculated, and tightly bound down to the deeper tissues, the primary tumour, which may be small and atrophic, is generally situated under the areola. If such a breast be sliced vertically, and treated with nitric acid, the spread of the cancer in the skin can often be distinctly made out in the form of miliary-like, or more irregular, opaque white deposits, united by a network of white lines, the latter corresponding to the lymphatic plexus, injected, as it were, with cancer cells. On the surface of the skin the cancerous main lymphatic trunks are not infrequently to be made out in the form of branching, cord-like elevations, radiating from the nipple.

The Suspensory Ligaments of Cooper.

But the subareolar plexus is not the only channel through which the lymphatics of the breast are brought into communication with those of the skin. If the mamma be sliced vertically, triangular tooth-like processes of breast tissue will be seen to pass from the anterior aspect of the main body of the gland, to end in fibrinous prolongations (the suspensory ligaments of Cooper) which reach the under surface of the true skin. Into these fibrous processes the parenchyma is protonged for a greater or less distance, and in spare women with well-developed mammæ it may reach to within a very short distance from the corium. From the side of the larger processes smaller secondary processes are given off, and by the junction of these with neighbouring processes a reticular arrangement is produced, the meshes of which are occupied by the subcutaneous fat. Similar peripheral processes containing parenchyma radiate from the circumference of the gland, and, after dividing up in the manner above described, they pass insensibly into the delicate connective tissue septa which separate the lobules of the circum-mammary fat. It is this entire absence of anything in the shape of a capsule to the breast, combined with the tapering off of the peripheral processes, which renders it so difficult for the surgeon to say when he has removed the whole mamma. These anatomical facts appear to have been fully recognised by such anatomists as Sir Astley Cooper and Henle, but until a comparatively recent date their practical importance was not appreciated by surgeons, or, if appreciated, disregarded, in consequence, no doubt, of the old idea that cancer was a constitutional disease, and, therefore, incurable by operation. To those who have not yet fully convinced themselves of the extensive distribution of the mamma, I would strongly recommend the study of the appearances presented by the breast tissue after treatment with nitric acid, typical illusirations of which will be found in my original paper already referred to. These peripheral processes of the mamma are not only of importance in giving a wide distribution to the parenchyma, but they are of equal importance, in that they carry with them lymphatic vessels which bring the lymphatics of the breast tissue proper into direct anatomical continuity with the lymphatics of the skin and subcutaneous tissue of the whole mammary area. It is by means of these lymphatic connections that microscopic miliary lenticular and nodular foci are disseminated, not only in the breast tissue proper, but frequently also in the skin and circum-mammary fat; and it is with the object of removing the whole area in which these are likely to be found that the modern extensive operation becomes necessary. I have, especially by the use of nitric acid, repeatedly demonstrated the presence of disseminated foci of disease upon the exposed surface of the parts removed, and have frequently found cancerous lymphatic emboli towards the inner margin of the breast when the primary tumour was situated in the outer hemisphere, and vice versâ.

In aggravated cases cancerous foci, both microscopic and macroscopic, are scattered in all directions, both in and around the breast. It will generally be found that those foci which occupy the subcutaneous tissue and circummammary fat are situated in the septa which separate the fat lobules. If these foci be examined microscopically they are usually found to have developed in the paravascular lymphatics, which, along with the small blood vessels, ramify in the septa. At other times miliary or shot-like cancerous foci are found close beneath or within the corium; and a careful search will sometimes reveal the presence of a cancerous paravascular lymphatic occupying one of the ligaments of Cooper or connective tissue septa leading up to the nodule. Fig. 4 shows a few cancer cells in a small lymphatic vessel accompanying the blood vessels which occupy one of the ligaments of Cooper, where there was a slight tacking down of the skin over the tumour. No better illustration could be afforded of the importance of free removal of that part of the skin which overlies the tumour-a point in the operation which is not always sufficiently attended to, especially when the tumour is placed peripherally. Fig. 3 is an example of a cancerous embolus in a large paravascular lymphatic which was found accompanying the vessels and nerves ramifying in one of the silvery connective tissue processes or "claws" which radiated from the edge of an ordinary circumscribed scirrhus into the circum-mammary fat towards the axilla.

The Retromammary Tissue and Pectoral Fascia.

Another situation in which cancerous lymphatics are very commonly met with is in the retromammary tissue and pectoral fascia, both of which, surgically speaking, should be regarded as forming an essential part of the breast. The body of the mamma is separated from the subjacent muscle by a thin stratum of connective tissue, the deeper fibres of which are more closely packed, to constitute the pectoral fascia proper. This fascia is very thin, and gives off many delicate processes, which pass between the fasciculi of the muscle ; the larger processes support the blood vessels which pass from the muscle to the gland. In obese subjects the retromammary tissue as well as the pectoral fascia are largely converted into fat, so that the fascia is scarcely recognisable as a distinct layer, in fact, anatomically speaking, there is no distinct line of separation between the retromammary tissue and the pectoral fascia. Delicate processes of breast tissue pass from the deep surface of the corpus mammæ into the retromammary tissue, and, as Heidenhain has shown, the parenchyma not infrequently extends into them as far as the pectoral muscle. It follows, therefore, that in order to remove the whole of the mammary parenchyma, the pectoral fascia, along with the superficial fibres of the pectoral muscle, should be removed. The retromammary tissue and pectoral fascia are of special importance to surgeons on account of the number of efferent lymphatics which leave the posterior surface of the mamma and ramify in them in the form of a. horizontal plexus, from which main trunks arise and pierce the axillary fascia to reach the axillary glands. That these efferent lymphatics are involved at a comparatively early stage of carcinoma is shown by the frequency with which adhesions are present when it is attempted to strip the fascia off the deep surface of the mamma. Moreover, it will often be observed that these adhesions are present although to the 
naked eye the tumour itself has not actually extended as far as the deep surface of the breast; they are analogous to the adhesions which produce the slight tacking down of the skin over a tumour situated at some little distance beneath it. In the majority of cases adhesion to the retromammary tissue takes place at an earlier date than to the skin, so that the efferent retromammary lymphatics, and consequently also the glands, are often infected at quite an early stage of the disease, and long before the skin is involved. If a carcinomatous breast, to which the retromammary tissue is adherent, be examined by the nitric acid method, delicate opaque white lines may often be seen radiating from the deep surface of the tumour into the retromammary tissue, and if these be examined microscopically they will be found to consist of cancerous lymphatic vessels which generally run in company with the blood vessels (paravascular efferent retromammary lymphatics). Often, however, even when cancerous, they are too small to be detected by the naked eye, in which case they are discovered more or less accidentally in microscopic sections, typical specimens of which are shown in Fig. 6, one of which is more magnified in Fig. 7 .

Enough has been said to show the great importance of removing the retromammary tissue and pectoral fascia, and flong with it the fascia covering the serratus magnus and the upper digitations of the external oblique of the abdomen; but while surgeons are now agreed as to the importance of removing these fasciæ, much difference of opinion still exists as to whether it is nfcessary to remove the pectoral muscle as well.

\section{The Pectoral Muscle.}

According to Heidenhain there is no necessity to remove the whole thickness of the pectoral muscle so long as no part of it is actually invaded by the tumour, but when once this invasion has occurred he urges the removal of the whole muscle, as the contraction of its fibres is favourable to early dissemination of the cancer cells throughout its substance. This teaching is founded upon the description of the lymphatics of the muscles by Sappey, who states that the lymph circulation is from the interior of the muscles towards the lymphatics of the investing fascia, and not from the fascia towards the muscle.

Rotter, ${ }^{10}$ as the result of a careful investigation into the jymphatics of the pectoral muscle, has come to the conclusion that the removal of the whole of the sternal fibres of the muscle should be a routine practice in the operation for cancer of the breast. In the first instance, he adopted this course, because he found it simpler than the removal of a thin layer of the muscle. Since the beginning of 1896 he has made a careful examination of the pectoral muscle in all the breasts he has removed, forty in number. He found that the perforating branches of the internal mammary and the superior tboracic artery, after penetrating the pectoralis major, could be traced through the retromammary tissue into the substance of the breast, and in one instance he succeeded in tracing a branch of the latter vessel into the tumour itself. Branches from the long thoracic could be traced through the muscle as far only as the retromommary fat. These are facts which are familiar to all anatomists, but Rotter was able to demonstrate that the blood vessels already mentioned were accompanied by efferent lymphatic vessels from the breast. Grossmann had already shown, by injections in the cadaver, that a lymphatic vessel could occasionally be demonstrated accompanying the superior thoracic artery and passing from the mamma along the posterior surface of the pectoralis major to the infraclavicular glands, this vessel receiving a lymphatic which proceeded from the first or pectoral set of axillary glands. Rotter has made the further important observation that one or two small glands were constantly found alongside the trunk of the superior thoracic artery, and that in one half of the specimens examined two or three other glands were found, generally in the angles of bifurcation of its branches, not more than three fingerbreadths from the perforating arteries. Other inronstant lymphatic g]ands were found behind the lower part of the pectoralis major, in relation to the branches of the external mammary artery. In a few instances a gland was dismvered in the substance of the pectoralis in relation to one of the perforating arteries. In rather more than a third of the carcinomatous breasts examined by Rotter, small cancerous nodules, visible to the naked eye, were found upon the posterior surface and in the substance of the pectoralis major, adjacent to the superior thoracic, at a distance varying from I to 2 inches from its origin from the axillary artery. These nodules, which could not be classed as cancerous infraclavicular glands, were placed between the pectoralis major and minor. Less frequently similar nodules were found relating to the peripheral branches of the artery. In one advanced case a cancerous gland was found related to one of the perforating arteries.

Out of the 15 preparations in which the retropectoral lymphatic glands were diseased, it is interesting to note that only in 5 was the muscle directly invaded by the tumour; in the remaining ro cases the tumour was separated from the muscle by a layer of retromammary fat of variable thickness. In the 18 cases in which there was no disease in the retropectoral lymphatics the tumour was adherent to the muscle in 5 instances, so that the invasion of the pectoral muscle was scarcely more frequent in the cases in which retropectoral dissemination existed.

As the result of the above observations Rotter came to the following conclusions :

I. That when the tumour invades the pectoral muscle directly, the latter does not become infected throughout, but through the main paravascular lymphatic channels above described.

2. That at an early stage of the disease, and before the tumour has become adherent to the pectoral fascia, the cancer cells may be conveyed through the retromammary fat and pectoral muscle to the lymphatic glands situated in the fascia upon the posterior surface of the pectoralis major, as well as by the more generally recognised channels to the axillary glands. That although dissemination is less regular by the former than by the latter channel, it nevertheless occurs in at least one-third of the cases, a frequency which renders removal of the pectoralis major necessary.

3. That these efferent lymphatics from the mamma only pass through the sternal portion of the muscle, and that the clavicular portion need not be removed unless large cancerous infraclavicular glands have become adherent to it.

Fig. 8 is from a section of a portion of the pectoralis major from a case of recurrent scirrhus in which the nodule was adherent to the muscle. It will be observed that the paravascular lymphatics which accompany the blood vessels and nerves of the muscles are distended with cancer cells ; small portions of the muscle are seen at the upper and lower margins of the figures.

If these important observations of Rotter are confirmed, there can be no question about the importance and necessity of removing the pectoral muscles in all cases. Cheyne, although he recommends that only the lower fibres of the pectoralis major should be removed in ordinary cases, is careful to point out that by so doing he is able, by pulling the muscle upwards, to remove all the fascia from its posterior surface, the cellular tissue between the pectorals, and the infraclavicular glands. The writer is inclined to think, however, that a less experienced operator than Mr. Cheyne would do well to take away both pectorals with the object not only of removing the retropectoral fascia and glands, but also of facilitating the thorough removal of all the glands, fat, and cellular tissue from the axilla.

\section{The Axillary Lymphatic Glands.}

Although I have gone fully into the normal and pathological anatomy of the axillary lymphatic glands in a former paper, I may here refer to one or two points which are of special practical importance. The number of lymphatic glands met with in the axilla is often far in excess of that usually described by anatomists, which may be readily accounted for by the fact that some of them are no larger than a pin's head, while others again frequently undergo such a marked adipose transformation as to be mistaken for ordinary fat lobules. This adipose change, of the nature no doubt of a functional involution, begins by a conversion of the connective tissue of the hilus into fat, and spreads towards the capsule, so that a narrow crescent of jymphoid tissue is all that remains of the essential structure of the gland. There is considerable evidence to show that these fatty lymphatic glands are probably also developed 
from fat lobules which are more closely related to the lymphatics than usual-that is to say, which possess afferent and efferent lymphaics, in the same way that some fat lobules possess an afferent artery and an efferent vein. I have occasionally observed the formation of lymphoid nodules containing germ centres in connection with the efferent paravascular lymphatics of the breast. It would be difficult to account for the large number of tuberculous glands which are so frequently met with in the neck, without some such new formation. These fatty involuted axillary glands are of interest to the surgeon both clinically and pathologically. As a rule palpation through the coverings of the axilla gives no indication of their presence; they are usually discovered when the axilla is explored from the wound made to excise the breast, and, as they are generally larger than non-involuted glands, they are either regarded as malignant, or are looked upon with the greatest suspicion. In stout women their resemblance to an ordinary fat lobule is such that they are liable to be overlooked by the surgeon who is content with exploring the axilla with the view of discovering and "shelling out" only those glands which are distinctly indurated. The point which the surgeon must bear in mind with regard to these fatty lymphatic glands is that they are just as liable to become affected as the typical glands.

It must be clearly understood that in its initial stage cancer of a lymphatic gland gives rise neither to enlargement nor to induration, and the absence, therefore, of these signs does not necessarily mean freedom from malignancy. No better proof of this statement could be adduced than that which is afforded by the condition of matters shown in Fig. 12, which represents a very early stage of glandular infection. The preparation was made to show the structure of a lymph atic gland which has undergone partial fatty involution. To the naked eye it showed no signs whatever of malignancy; indeed, in consequence of the fatty change it was softer than an ordinary gland made up entirely of lymphoid tissue. It will be observed that the disease in the gland is represented merely by a few small clusters of cancer cells occupying the subcapsular lymph sinus into which the afferent lymphatics open. The specimen becomes still more interesting from the fact that the gland was no larger than a small pea, and that the other glands from the axilla were still smaller, and healthy. The primary growth was a small and somewhat atrophiclooking scirrhus, and was separated from the pectoral fascia by a layer of retromammary fat about one-third of an inch thick.

Although cancerous glands are so commonly and so abundantly met with in the axilla, cancerous afferent and efferent lymphatic vessels are not found so frequently as one would expect, a point to which attention has also been directed by Joerss, who suggests that infection from one gland to another takes place rather by embolism than by direct extension along the lymphatic vessels. Fig. II shows a transverse section of a thickened lymphatic trunk which was found in the axillary fat at a considerable distance from a cancerous gland. The bundles of non-striped muscle are seen in the vessel, while three or four cancerous emboli are seen floating freely in its lumen. More frequently the cancer cells are found to completely plug the lumen of the vessels. A third condition I have met with is that in which the cancer cells occupy the lymph spaces of an organised lymphatic thrombus. In Fig. 9, which is taken from the tissue immediately outside a cancerous lymphaticgland, several of the afferent lymphatics are seen to be plugged with deeply-stained cancer cells.

Surgeons when examining the axilla are not infrequently in the habit of referring to a "thickening " of the lymphatics to be felt not only when the axilla is opened up, but even through its covering. I am satisfied that the lymphatics are in no way responsible for this condition, which is met with most distinctly in spare women. The feeling is due to the presence of the ducts of the breast tissue, which run like so many branched and ratherill-defined strings upon the surface of the serratus, often as high up in the axilla as the third rib. They are, in fact, the ducts belonging to what Spence used to speak of as the axillary tail of the mamma, and the more widespread the breast tissue the better, as a rule, are they to be felt. That this is the case may readily be demonstrated by stripping off the fascia from the posterior surface of the breast and treating with nitric acid, when the structures in question appear as branching opaque white lines, which may occa- sionally be traced close up to, but not into, cancerous glands. Microscopic examination shows that these white lines are not lymphatics, but mammary ducts. One may examine both macroscopically and microscopically the tissue from many cancerous axillæ, without being able to discover any disease whatever in the lymphatic trunks. It would appear, therefore, that as soon as the cancer cells reach the main lymphatics they are swept along them to the glands in the form of an embolus. Cancerous emboli are also to be found in the smaller lymphatics of the axilla, and these, of course, are only to be discovered by microscopic examination. The emboli may invade the wall of the lymphatic and give rise to nodules of cancer which are distinct from the lymphatic glands. In the comparatively few cases in which I have found the main trunks diseased, the cancer cells could always be traced as far as a malignant gland. It is very doubtful whether a cancerous condition, even of the largest axillary lymphatics, could be detected during an operation.

The lymphatic glands which are first involved are the pectoral group, which lies on the anterior part of the inner wall of the axilla, along the line of the long thoracic artery. In the later stages of the disease, the glands towards the apex of the axilla, those alongside and behind the vein, as well as those below the clavicle, and the posterior group lying along the course of the subscapular vessels and nerves may alp become involved.

It must be distinctly understood, however, that the glands towards the apex of the axilla and beneath the clavicle may be diseased while the pectoral glands are normal. There are two points which I think are not sufficiently attended to in clearing out the axilla; the one is the removal of the fascia over the serratus, which cannot be done satisfactorily unless some of the fibres of the muscle are dissected away along with it; and the other pcint is, that in removing the glands from the neighbourhood of the axillary vein, the sheath of the latter should be taken away; one has only to dissect the axilla, in a formalin-hardened subject, to realise the close relation of the main lymphatic trunks to the vein. It is advisable, moreover, to remove the branches of the axillary vein which proceed towards it from the chest, since they also. are accompanied by lymphatics. The subseapular nerves should be spared if possible, since they supply muscles which are important in carrying out the movements of the shoulder.

The Supraclavicular Glands.

As regards the supraclavicular glands it is very difficult to say whether or not their removal should, as recommended by Halsted, form part of the routine operation. The researches of Halsted and his assistants have shown that these glands are more frequently diseased than surgeons were inclined to believe, and that, just as in the axilla, without manifesting any evidence of such a condition to the naked eye. There can be no doubt that the removal of these glands is called for if cancerous glands are found occupying the highest position that can be reached by the axillary route, because the glands in the posterior triangle of the neck may be cancerous without. affording any clinical evidence.

Although Halsted recommends and practises the clearingout of the supraclavicular region in every case of cancer of thebreast, most surgeons will, I think, be disposed to await the results of the microscopic examination of the tissues removed from this region before following his example.

What we specially wish to learn is: ( 1 ) In what proportion of cases can cancer be demonstrated microscopically without there being any evidence of its existence to palpation; (2) what is the proportion of cures in cases in which these glands werefound to be diseased? Upon the answer to the latter question will rest the decision as to whether infected supraclavicularglands constitute a contraindication to operation.

\section{Operation.}

The thorough operative procedures adopted by Cheyne, Halsted, and Kocher ${ }^{11}$ have been so ably and clearly described in their writings, that for me to append a systematic account of the operation which is called for in cancer of the breast, would be superfluous. To those who have not access to Halsted's papers, I may refer to Mr. Butlin's excellent description of that surgeon's operation, published, with illustrations, in the British Medical Jodrnal for December 3 rd, 1898 . 
As the result of my own personal investigations I certainly concur with $\mathrm{Mr}$. Watson Cheyne, who says: "I may add my firm conviction that the patient's chance lies in the first operation. If this fails, either from imperfect removal of the disease, or on account of the extent of the disease in the first instance, further operation, however extensive, is seldom successful."

1 Heidenhain, L., Arch. f. klin. Chir., Bd. xxxix. 2 stiles, Harold J. Edin. Med. Journ., June and July, 1892.3 Cheyne, W. Watson, Lancet, 1899. 4 Ruffer, A., and Plimmer, H. G., Journ. Path. and Bacteriol., 1893. 5 Sanfelice, Ztschr. f. Hyg., 1899. ${ }_{6}$ Plimmer, H. G., Lancet and Practitioner, 1899. 7 Halsted, W. S., Annals of Surgery, 1898.8 Goldmann, Edwin, Beitr. z. klin. Chir. 1897.' 9 Karg, C., Deutsche Ztschr. f. Chir., 1892.
10 Rotter, J., Arch. f. klin. Chir, Bd. lvii. 11 Kocher, Th., Chirurgische operationslehre, Dritte Auflage, 1897 .

\section{The PROBable PARENTAL FORM OF THE SHARP-TAILED FILARIA FOUND IN THE BLOOD OF THE ABORIGINALS _OF BRITISH GUIANA.}

[WITH SPECIAL PLATE OF PHOTOMICROGRAPHS.]

By C. W. DANIELS, M.B., M.R.C.S.

Colonial Medical Service, British Guiana.

IT is now known that two forms of filarial embryos-a blunttailed and a sharp-tailed-occur in the blood of a large proportion of the aboriginals of British Guiana. In the BRITISH Medical Journal of April 16th, 1898, I described some adult filariæ found in two of these aboriginals, and showed that they were the parental forms of one of the blood worms referred to (described and provisionally named "Filaria Ozzardi" ${ }^{1}$ by Dr. Manson in the British Mrdical Journal of December 25th, 1897)-namely, the blunt-tailed.

In the course of a post-mortem examination of a third aboriginal in whose blood both the blunt and sharp-tailed filariæ had been found (and no others in repeated examinations-two of them at night), I found a few adult filariæ of the species previously described, and, in addition, a female and the portion of a male new to me, and probably the parental form of the sharp-tailed embryos.

These two worms lay close together, and were found on stripping the peritoneum from the anterior abdominal wall. They were partly detached in the process, and consequently must have been lying in the subperitoneal connective tissue. They were arranged in loose coils, and did not appear to be either encysted or contained in any vessel. They were dead. The general structure-an unarmed head, complete alimentary canal, double ovarian tube opening into a single rather complicated vagina, smooth surface-was similar to that of the other filaria alluded to, and closely resembled Filaria Bancrofti.

The subjoined table gives my measurements of this and the other known adult hæmatozoal filariæ of approximately similar dimensions; that found by Magalhäes at Rio de Janeiro is so much larger that it may be excluded from the comparison.

\begin{tabular}{|c|c|c|c|}
\hline & $\begin{array}{c}\text { Filaria } \\
\text { Bancrofti. }\end{array}$ & $\begin{array}{c}\text { Filaria } \\
\text { No. I. } \\
\text { (Filaria perstans.) }\end{array}$ & $\begin{array}{c}\text { Filaria } \\
\text { No. 2. } \\
\text { (Filaria } \\
\text { Ozzardi.) }\end{array}$ \\
\hline $\begin{array}{ll}\text { Length } \ldots ̈ & \ldots \\
\text { Greatest thickness } & \ldots \\
\text { Diameter of head } & \ldots \\
\text { Diameter of neck } & \ldots \\
\text { Distance from head-... } \\
\text { (r) Of vaginal outlet } \\
\text { (2) Of ovarian opening... } \\
\text { Distance from tail of anai } \\
\text { papilla... } \\
\text { Termination of tail }\end{array}$ & \begin{tabular}{|c|}
$\mathrm{Mm}$. \\
85 to 90 \\
0.20 to 0.26 \\
0.055 \\
0.049 \\
0.710 \\
0.920 \\
0.225 \\
Blunt, cir- \\
cular, not \\
bulbous.
\end{tabular} & $\begin{array}{l}\text { Mm. } \\
\text { 70 to 80 } \\
\text { o.r20 } \\
0.070 \\
0.054 \\
0.600 \\
? \\
\text { a.r45 } \\
\text { Slightly bulbous; co- } \\
\text { vered by thickened } \\
\text { cuticleprolonged into } \\
\text { two triangular ap- } \\
\text { pendages. }\end{array}$ & $\begin{array}{c}\text { Mm. } \\
81 \\
0.210 \\
0.050 \\
0.039 \\
0.710 \\
0.850 \\
\\
\text { o.230 } \\
\text { Bulbous, } \\
\text { cuticle not } \\
\text { thickened. }\end{array}$ \\
\hline
\end{tabular}

From this table it will be seen at once that the new filaria is sharply differentiated from the other aboriginal filaria by its smaller head, larger body, and the absence of caudal cuticular appendages. On the other hand, its resemblances to Filaria Bancrofti are very marked. The vaginal outlet is as strongly marked as in that worm, and consists of a straight tubal terminal portion continuous with an irregular convoluted portion into which the two ovarian tubes open together. I do not find any widely-dilated portion such as I believe exists in Filaria Bancrofti.

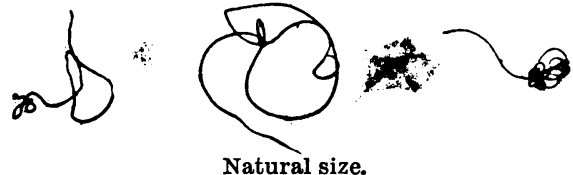

The shape of the body differs in these two worms. In Filaria Bancrofti the thickness for the greater part of the worm is fairly uniform, but it tapers slightly towards the head for a short distance from the vulva, and then more abruptly to the neck. In the new filaria the greatest thickness is about the junction of the anterior third with the rest of the body ; from this point it tapers gradually towards the head, tapering more rapidly for a considerable distance from the vaginal outlet to the neck, without any abrupt change. The termination of the tail also differs in being distinctly bulbous, measuring $0.038 \mathrm{~mm}$. at a distance of $0.017 \mathrm{~mm}$. from the tip, and 0.034 at $0.04 \mathrm{~mm}$. from the tip of the tail.

The portion of the male found was about $38 \mathrm{~mm}$. in length. In thickness it was nearly $0.2 \mathrm{~mm}$. ; in marked contrast with the $0.11 \mathrm{~mm}$. of the male Filaria Bancrofti, or the 0.06 of the male of the other aboriginal filaria. The tail was tightly coiled. There were no protruded spicules; but without running the risk of damaging the specimen a thorough examination of this feature was impossible. The tip of the tail protruded from the coil. It slowly tapered to a point $0.27 \mathrm{~mm}$. from the tip, where it abruptly tapers. This point probably marks the point of emergence of the spicules. The gradual taper ending in a faintly bulbous tip in this worm, is very different from the termination of the tail in Filaria Bancrofti.

It is obvious that the powerful body and small head of this worm are better suited for extensive wanderings than the larger head and weaker body of the aboriginal filaria previously found. If its habitat is the connective tissue, as seems probable, it will be very difficult to find; in two previous examinations in which the sharp-tailed embryos had been found $I$ failed to find the corresponding adult worms. Under the circumstances I leave the details of structure, and particularly the character of the embryos in the ovarian tubes, for further examination, as they could not be determined without risk of damaging or altering the specimens.

The differences observed both in the male and female are sufficient, I consider, to differentiate this from the other described adult filariæ. The name "Filaria Ozzardi" might be retained for the new species.

1 [We are informed that Dr. Manson has recently found these adult flariæ to be identical with the parental form of the African Filaria perstans. The blunt-tailed form of the so-called Filaria Ozzardi, is thereFrancis Fowke from specimens sent home by Dr. Daniels.]

Mr. HenRy AlLeN, of Ecclesall, who died on February 23rd last, has bequeathed $£ 250$ each to the Sheffield Infirmary Sheffield Royal Hospital, Sheffield Children's Hospital, and the Jessop Hospital.

The Antirabic Institute of TuRin.-The official report of this institution states that the number of persons who applied for treatment during the year 1898 was $44 \mathrm{I}$. Of these 23I. underwent a course of treatment by Pasteur's method ; in the remaining 210 cases it was positively ascertained that the animal which inflicted the bite was not rabid. The mortality was nil. The total number of persons who have applied for treatment since the opening of the institute on September 3 oth, 1886 , is 5,169 ; of these 3,627 . were actually treated. The total death-rate from 1836 to 1898 (inclusive) is givon a? cofis per cent. 